\title{
Die Aether der b-Phosphorsäure, c-Phosphorsäure und Kohlensäure.
}

Man erhält sie nach Philippede Clermont auf folgende Weise:

b-Phosphorsäureäther, pyrophosphorsaures Aethyloxyd $=2 \mathrm{C}^{4} \mathrm{H}^{5} \mathrm{O},{ }^{6} \mathrm{PO}^{5}$. Reines trocknes Jodithyl wird mit zur Zersetzung mehr als hinreichendem, völlig trocknem pyrophosphorsaurem Silberoxyd in einem zugeschmolzenen Probirkolben im Wasserbade einige Zeit erhitzt. Es entsteht Jodsilber und halbphosphorsaures Aethyloxyd nach folgender Gleichung:

$$
2 \mathrm{AgO},{ }^{b} \mathrm{PO}^{5}+2 \mathrm{C}^{4} \mathrm{H}^{5} \mathrm{~J}=2 \mathrm{AgJ}+\left(2 \mathrm{C}^{4} \mathrm{H}^{5} \mathrm{O}^{\mathrm{b}} \mathrm{PO}^{5}\right) \text {. }
$$

Die Masse wird mit Aether ausgezogen, von dem filtrirten Auszuge der Aether abdestillirt und der Rückstand durch einen trocknen Luftstrom bei $130^{\circ} \mathrm{C}$, zuletzt im Vacuum bei $140^{\circ} \mathrm{C}$. von anhängendem Jodäthyl und Aether befreit. Er besteht aus Pyrophosphorsäureäther $\left(2 \mathrm{C}^{4} \mathrm{H}^{5} \mathrm{O}\right.$, $\left.{ }^{6} \mathrm{PO}^{5}\right)$.

Dieser bildet eine farblose zähe Flüssigkeit von brennendem Geschmack, eigenthiimlichem Geruch. Spec. Gew. $=1,172$ bis 1,175 bei $17^{\circ} \mathrm{C} .,=1,191$ bei $0^{0} \mathrm{C}$. Iöslich im Wasser, Alkohol und Aether. Wird an der Luft sauer und zieht aus derselben rasch bis zu 14 Procent Wasser an. Löst kleine Mengen von Jodsilber auf, die beim Stehen herauskrystallisiren. Brennt mit weisslicher Flamme unter Verbreitung weisslicher Dïmpfe. Zerlegt sich beim Versuche ihn zu destilliren. Bei 200-2100 C. verkohlt er, wird sauer und liefert ein Destillat, welches gemeinphosphorsaures Aethyloxyd oder c-Phosphorsäureäther $\left(3 \mathrm{C}^{4} \mathrm{H}^{5} \mathrm{O},{ }^{\mathrm{C}} \mathrm{PO}^{5}\right)$ ist. Aetzkalilauge zersetzt den Pyrophosphorsäureäther unter Bildung eines zerfliesslichen Salzes.

Der Pyrophosphorsäureäther wurde zuerst von Moschnin im Laboratorium von $W$ urtz erhalten.

c-Phosphorsäureäther. Drittelphosphorsaures Aethyloxyd $=3 \mathrm{C}^{4} \mathrm{H}^{5} \mathrm{O},{ }^{\mathrm{c}} \mathrm{PO}$, entsteht durch Einwirkung von 3 Aeq. Jodäthyl auf 1 Aeq. $3 \mathrm{AgO}^{\mathrm{O}}{ }^{\mathrm{c}} \mathrm{PO}^{5}$ im verschlossenen Gefässe im Wasserbade. Aether löst aus dem Gemenge das phosphorsaure Aethyloxyd auf. Im leeren Raume destillirt das letztere erst bei $140^{\circ} \mathrm{C}$. unzersetzt. In lufthaltigen Gefässen destillirt es unter theilweiser Zersetzung erst bei $210^{\circ} \mathrm{C}$.

Das phosphorsaure Aethyloxyd ( $\left.3 \mathrm{C}^{4} \mathrm{H}^{5} \mathrm{O}, \mathrm{PO}^{5}\right)$ ist eine farblose ölähnliche Flüssigkeit von eigenthümlichem 
Gexuch, brennendem Geschmack. Mit Wasser mischbar, zu einer sauer reagirenden Flüssigkeit sich zerlegend. Verbrennt mit weisslicher Flamme unter Ausstossung weisser Dämpfe. Spec. Gew. 1,086 bei $0^{0} \mathrm{C}$. Beginnt bei $210^{\circ} \mathrm{C}$. zu sieden, dic Temperatur steigt rasch auf 240 bis $2500 \mathrm{C}$., dabei verkohlt es und lässt einen sauren Rückstand.

Durch Einwirkung einer Lösung von trocknem Ammoniakgas in absolutem Alkohol auf Phosphorsäureäther in zugeschmolzener Röhre bei $250^{\circ} \mathrm{C}$. erhält man phosphorsaures Aethyloxyd-Ammoniak und Aethyliak nach folgender Gleichung:

$$
\begin{gathered}
2 \mathrm{H}^{3} \mathrm{~N} \\
2\left(3 \mathrm{C}^{4} \mathrm{H}^{5} \mathrm{O}, \mathrm{PO}^{5}\right)=\mathrm{C}^{4} \mathrm{H}^{7} \mathrm{~N} \\
\left.2 \mathrm{C}^{4} \mathrm{H}^{5} \mathrm{O}^{\circ} \mathrm{PO}^{5}\right) . \\
. \mathrm{H}^{4} \mathrm{NO},
\end{gathered}
$$

Beim Destilliren des Rückstandes entweichen Aethyliak, Ammoniak und Weingeist und es bleibt eine Flüssigkeit, die beim Erkalten krystallisch erstarrt. Die Krystalle sind phosphorsaures Aethyloxyd-Ammoniak = $\left(\mathrm{H}^{4} \mathrm{NO}^{2} \mathrm{C}^{4} \mathrm{H}^{5} \mathrm{O},{ }^{\mathrm{e}} \mathrm{PO}^{5}\right)$.

Kohlensïureäther $=\mathrm{C}^{4} \mathrm{H}^{5} \mathrm{O}, \mathrm{CO}^{2}$. Man erhitzt 1 Aeq. kohlensaures Silberoxyd mit etwas mehr als 1 Aeq. Jodäthyl in der verschlossenen Glasrölire. Durch Destillation erhält man aus dem Rückstande Kohlensäureäther als ein sehr flüssiges Liquidum, von brennendem Geschmack, angenehmem Geruch, bei $126^{\circ} \mathrm{C}$. siedend und mit bläulicher Flamme bremend. (Ph. de Clermont; Ann. de chim. et de phys. Juillet 1855. T. XLIV. p. 330-336.)

$$
\text { Dr. H. Ludvig. }
$$

\section{Butylverbindungell.}

A. Wurtz entdeckte im Fuselöl des Branntweins aus Runkelrübemmelasse den Butylalkohol und untersuchte dessen Derivate genauer.

Das rohe Runkelrübenfuselöl siedet zwischen 80 und $132^{\circ} \mathrm{C}$. und ist ein Gemenge aus Amylalkohol, Butylalkohol, Weingeist und Wasser. Durch fractionirte Destillation, Auffangen des zwischen 105 und $115^{\circ} \mathrm{C}$. Uebergehenden für sich, öftere Rectification desselben, 48stiindiges Kochen mit Kalilauge in einem Apparate, in welchem die entwickelten Dümpfe abgekühlt werden und wieder in das Kochgefäss zurückfliessen können, Rectificationen, bis der Siedepunct zwischen 108 und $110^{\circ} \mathrm{C}$. stationär bleibt, erhält man den Butylalkohol hinlänglich rein. Absolut rein lingegen erhielt ihn $W u r t z$ 